\title{
REPRESENTAÇÕES SOCIAIS DOS PARTICIPANTES DE PROJETO ESPORTIVO DE VITÓRIA
}

\author{
SOCIAL REPRESENTATIONS OF PARTICIPANTS IN VITÓRIA'S SPORTS \\ PROJECT
}
REPRESENTACIONES SOCIALES DE LOS PARTICIPANTES DEL PROYECTO DEPORTIVO DE VITÓRIA

\author{
André da Silva Mello*, Jéssica de Souza Silva*, Renata Silva Jorge*, \\ Omar Schneider*, Wagner dos Santos*
}

\begin{abstract}
Palavras chave: Projetos de investimento social. Esportes juvenis. Valores sociais.

Resumo: 0 objetivo da pesquisa é analisar as representações sociais que os adolescentes participantes das Escolinhas de Esportes de Vitória/ES têm sobre esse projeto social. Trata-se de uma pesquisa descritivo-interpretativa, ancorada na Teoria das Representações Sociais. Como fonte na produção dos dados, realiza entrevistas semiestruturadas com 108 participantes do projeto. No processo de interpretação, utiliza o software Iramuteq, por meio das seguintes estratégias analíticas: nuvem de palavras, análise de similitudes e classificação hierárquica descendente. Como resultado, constata que a palavra "jogar" constitui o núcleo central das representações sociais dos entrevistados. Os sentidos vinculados ao jogar estão relacionados com a amizade, o aprender as modalidades esportivas, a estética/saúde, a ascensão social e com novas perspectivas de vida. Para além dessas figuras do aprender, identifica representações associadas ao caráter moralista dos projetos sociais.
\end{abstract}

Keywords: Social investment projects. Youth sports. Social values.

Palabras clave: Proyectos de inversión social. Deportes juveniles. Valores sociales.

\begin{abstract}
The study analyzes social representations of teenagers who are members of Sports Schools in Vitória/ES about that social project. It is a descriptive-interpretative study anchored in the Social Representations theory. For data collection, semi-structured interviews were carried out with 108 participants in the project. Interpretation uses the Iramuteq software through the following analytical strategies: word cloud, analysis of similarities, and descendant hierarchical classification. As a result, the work determines that the word playing is the core of respondents' social representations. Meanings linked to playing are related to friendship, learning sports disciplines, esthetics/health, social rise and new perspectives in life. Beyond such learning images/figures, it identifies representations associated to the moralist nature of social projects.
\end{abstract}

*Universidade Federal do Espírito Santo. Vitória, ES, Brasil.

E-mail: andremellovix@gmail.com; jejelsouza@gmail.com; renatasjmax@ hotmail.com; omarvix@gmail.com; wagnercefd@gmail.com

Recebido em: 16-06-2016 Aprovado em: 11-03-2017

DOI: http://dx.doi.org/10.22456/1982-8918.65543 jugar se relacionan con la amistad, el aprender las modalidades deportivas, la estétic salud, la ascensión social y nuevas perspectivas de vida. Además de estas figuras del aprender, se identifican representaciones asociadas al carácter moralista de los proyectos sociales.

\section{(c) (1) () Licence}




\section{INTRODUÇÃO}

No Brasil vem crescendo o número de projetos sociais vinculados às atividades físicas e esportivas, tanto no âmbito das instituições públicas quanto das privadas. Esses projetos são destinados, em sua maioria, às crianças e adolescentes das periferias dos grandes centros urbanos do país e apresentam como discurso principal a ocupação do tempo livre desses indivíduos (GONÇALVES, 2003; GUEDES et al., 2006; THOMASSIM, 2007). Os projetos sociais focalizam, majoritariamente, a inclusão social, constituindose como alternativa de lazer para adolescentes e jovens em situação de vulnerabilidade social'. São considerados "antídotos" contra processos de socialização negativos advindos de contextos dominados pela violência, pelo tráfico de drogas e com estrutura sociocultural degradada.

Melo (2012) e Silveira (2013) afirmam que parte significativa desses projetos está vinculada às políticas compensatórias e assistencialistas, cujo foco principal é amenizar as desigualdades decorrentes de um sistema político-econômico que perpetua as injustiças sociais. Demo (1995) já fez essa crítica, pois, para ele, as ações sociais do Poder Público estão centradas na manutenção da institucionalidade, por meio de políticas públicas de esporte e de lazer baseadas em uma abordagem sistêmica, que busca diminuir as pressões sociais sem, no entanto, alterar as condições estruturais que as geram.

Simultaneamente ao aumento do número de projetos sociais, também proliferam a representação e a convicção de que as atividades físicas e esportivas são benéficas à educação de adolescentes e jovens, constituindo a narrativa central de políticas sociais destinadas à proteção desse público (CASTRO; SOUZA, 2011; GUEDES et al., 2006; MELLO, 2007; ZALUAR, 1994). Predomina a crença de que, por meio da prática de atividades físicas e esportivas, jovens e adolescentes poderão adquirir conteúdos simbólicos, como a incorporação de valores e comportamentos que os levarão a novas perspectivas de vida.

Aliados a essa representação, os projetos sociais, em sua grande maioria, apoiamse em uma concepção idealizada de adolescência e juventude, estigmatizando esses grupos sociais com discursos pejorativos (FREITAS, 2000). Burak (2001) alerta sobre 0 desenvolvimento, nas últimas décadas, de uma visão negativa geral desses indivíduos, que são facilmente julgados na sociedade contemporânea pelos seus sucessos negativos, ${ }^{2}$ tomando todos por iguais. Nesse sentido, a adolescência e a juventude são vistas como fases de transição, de turbulência e de incertezas. Essa concepção tem justificado a implantação de políticas esportivas destinadas a esse público, assentadas em discursos moralistas. A compreensão das atividades físicas e esportivas como "panaceia" para as mazelas sociais, somada à visão pejorativa sobre a adolescência e juventude, gera práticas e representações homogeneizantes em relação aos projetos sociais que, geralmente, desconsideram a pluralidade cultural presente em contextos complexos e singulares (MELLO, 2007; MELO, 2004; THOMASIM, 2006; VILAÇA; GAWRYSZEWSKI; PALMA, 2014).

Apesar da expansão das atividades físicas e esportivas nos projetos sociais, poucos são aqueles que consideram, em suas intervenções pedagógicas, os interesses, necessidades e expectativas dos seus participantes. Tal fato tem gerado dificuldade de retenção e contribui

1 Carneiro e Veiga (2004) definem vulnerabilidade como exposição a riscos, com baixa capacidade material, simbólica e comportamental de famílias e grupos para enfrentar os desafios com que se defrontam na sociedade contemporânea. Indivíduos são vulneráveis quando não dispõem de recursos para lidar com êxito com os riscos a que estão submetidos.

2 Êxito em atividades social e moralmente condenáveis, por exemplo, pichação do patrimônio público. 
para elevar os índices de evasão nesses projetos, o que justifica a análise da divergência entre as intenções dos gestores e as expectativas dos seus usuários (VIANNA; LOVISOLO, 2009). Segundo Mello, Ferreira Neto e Votre (2009), bem como Vianna e Lovisolo (2011), ao pensarmos na mediação da Educação Física com participantes de projetos sociais, é preciso considerar as racionalidades locais e os motivos para a ação desses indivíduos, ou seja, é necessário compreender os sentidos que os indivíduos atribuem às atividades físicas e esportivas. Lovisolo (1995) afirma que, sem as experiências do cotidiano e sem as representações dos seus usuários, os projetos podem chegar a conclusões imprecisas e traçar estratégias inadequadas de intervenção.

A fim de contribuir para superar essa lacuna, a presente pesquisa tem como objetivo analisar as representações sociais que os adolescentes participantes do projeto Escolinhas de Esportes de Vitória/ES têm sobre esse projeto. Almejamos, com isso, analisar os sentidos que eles construíram na relação com as atividades esportivas.

\section{METODOLOGIA}

A pesquisa descritivo-interpretativa, ancorada na Teoria das Representações Sociais (MOSCOVICl, 2003), com foco no núcleo central das representações sociais (ABRIC, 2000; 2003; SÁ, 2002), foi a perspectiva teórico-metodológica empregada neste estudo. Entendemos representações sociais - centradas nas ações concretas e linguageiras - como formas de agir e pensar geradas nas atividades de comunicações dos membros de determinados grupos sociais. Essas representações correspondem a um conjunto de saberes práticos, do senso comum, que tem sua gênese nos processos de comunicação de uma comunidade discursiva (MOSCOVICl, 2003).

Dessa forma, representar é mais do que reproduzir o objeto da representação; é dele apropriar-se e, nesse processo de apropriação, reconstituí-lo e modificá-lo. Como afirma Moscovici (2003, p. 45), "[...] longe de serem receptores passivos, os indivíduos pensam por si mesmos, produzem e comunicam incessantemente suas representações próprias e específicas". Representações sociais constituem um campo de conhecimento e prática dos indivíduos, formado nos universos consensuais, que lhes permite expressar suas opiniões, seus pontos de vista e suas atitudes, bem como seus comportamentos em situações concretas.

Com base nessa característica dinâmica e particular, a Teoria das Representações Sociais busca compreender as racionalidades de grupos sociais específicos, explicitando os seus motivos para a ação. As representações sociais se apresentam como um conjunto estruturado de informações, crenças, opiniões e atitudes composto de dois subsistemas: central e periférico. $O$ sistema central constitui as crenças, valores e atitudes associados ao objeto da representação, enquanto o periférico está articulado às características individuais, ao contexto imediato e contingencial. Por isso, segundo Sá (2002), a Teoria do Núcleo Central atribui aos elementos do sistema central as características de estabilidade, rigidez e consensualidade e aos elementos do sistema periférico o caráter mutável, flexível e individual.

Com base nesses pressupostos, buscamos compreender os sentidos que os adolescentes participantes das Escolinhas de Esportes, projeto social ${ }^{3}$ desenvolvido pela

3 Compreendemos projeto social como "[...] um empreendimento planejado, que consiste num conjunto de atividades inter-relacionadas 
Secretaria Municipal de Esportes de Vitória, atribuem a esse projeto. Nele, são ofertadas as seguintes modalidades: futsal, futebol de areia, futebol society, futebol de campo, basquete, handebol, judô, natação, vôlei, balé, ginástica rítmica, tênis de mesa, tênis de campo, hidroginástica, canoagem, remo e atletismo.

Distribuídas em 22 núcleos, as Escolinhas de Esportes contam com a participação de $4.470^{4}$ crianças e adolescentes, 30 professores, com formação em Educação Física, um coordenador e uma auxiliar administrativa. Os núcleos das Escolinhas de Esportes, distribuídos nas nove Regiões Administrativas ${ }^{5}$ de Vitória, buscam democratizar o acesso ao esporte para crianças e adolescentes de sete a 17 anos. As vagas são destinadas, prioritariamente, a alunos da rede pública de ensino.

As atividades do projeto são desenvolvidas de segunda a sexta-feira, das $8 \mathrm{~h}$ às 11 horas e das $14 \mathrm{~h}$ às 17 horas, com exceção das escolinhas de Jardim da Penha e da Fonte Grande, que funcionam a partir das 18 horas. As aulas de cada modalidade ocorrem duas ou três vezes por semana, variando de acordo com o núcleo, com duração de 60 minutos. Embora a coordenação do projeto realize reuniões formativas quinzenais, centradas no compartilhamento das experiências desenvolvidas nos diferentes núcleos, não há um único procedimento metodológico adotado por todos os docentes, mas, sim, orientações pedagógicas para que eles considerem em suas intervenções o objetivo principal do projeto.

Paracompreenderas representações que os participantes têm sobre oprojeto, realizamos 108 entrevistas semiestruturadas, ${ }^{6}$ que foram distribuídas por Regiões Administrativas (12 entrevistas por região, em nove regiões), gênero e faixa etária. ${ }^{7}$ Inicialmente, com a intenção de "quebrar o gelo" e deixar os adolescentes à vontade, fizemos perguntas mais diretas, relacionadas com os seguintes aspectos: nome, idade, tempo de adesão ao projeto, como 0 conheceu, local de residência e série escolar. Posteriormente, perguntamos aos entrevistados: o que o projeto Escolinhas de Esportes significa para você? A partir dessa pergunta, outras questões relacionadas com os sentidos atribuídos pelos participantes ao projeto surgiram na interlocução com eles. Cada entrevista durou, em média, oito minutos.

No processo de análise, utilizamos o software Iramuteq. Desse instrumento, que permitiu identificarmos o núcleo central e as diferentes representações dele derivadas, apropriamo-nos das seguintes estratégias de análise: a) nuvem de palavras; b) análise de similitudes; e c) classificação hierárquica descendente. Em caráter complementar a esses métodos, que estão baseados na classificação e sistematização das palavras presentes nas narrativas dos entrevistados, utilizamos fragmentos de suas falas para analisar os sentidos que eles construíram sobre o projeto. Também participamos de dois festivais esportivos, que permitiram que conversássemos com os entrevistados e conhecêssemos mais o que pensam sobre as atividades ofertadas pelas Escolinhas de Esportes.

e coordenadas, para [...] transformar uma parcela da realidade, diminuindo ou eliminando um déficit, ou solucionando um problema social" (BELO HORIZONTE, 2007, p. 87). As Escolinhas de Esportes constituem um projeto social coordenado pela Secretaria de Esportes de Vitória/ ES e, atualmente, faz parte do Programa Educação Ampliada. O projeto se configura como uma política de Estado, que perdura há dez anos e tem como objetivo principal: "[...] desenvolver valores sociais e melhoria na autoestima, no convívio, na interação e na promoção da saúde de crianças e adolescentes de bairros periféricos de Vitória/ES" (Disponível em: <http://www.vitoria.es.gov.br/cidadao/vitoria-mantem-escolinhasde-esportes-gratuitas-em-19-locais>). Acesso em: 5 ago. 2015.

4 Número de participantes em março de 2016.

5 Dado retirado do site da Prefeitura Municipal de Vitória: <http://legado.vitoria.es.gov.br/regionais/home.asp>. Acesso em: 24 set. 2015 , às $14 \mathrm{~h} 55 \mathrm{~min}$.

6 número de entrevistas foi delimitado por meio do cálculo amostral, que define uma amostra significativa de sujeitos em relação à população total, que é de 4.470 participantes.

7 Baseados no Estatuto da Criança e do Adolescente, consideramos adolescentes os indivíduos com idade entre 12 e 18 anos. 
A interpretação dos dados ocorreu no diálogo, sobretudo com a Teoria da Relação com o Saber, de Bernard Charlot (2000, 2001), com os Estudos do Cotidiano, de Michel de Certeau (1994) e com a Análise de Discurso Crítica (FAIRCLOUGH, 2003; RESENDE; RAMALHO, 2006), além do cotejo com produções específicas sobre atividades esportivas e projetos sociais.

\section{APRESENTAÇÃO E ANÁLISE DOS DADOS}

Depois de transcritas e codificadas, as entrevistas foram inseridas no software Iramuteq, que explicitou a palavra "jogar" como a mais recorrente entre as expressões que os sujeitos atribuem ao projeto Escolinhas de Esportes de Vitória, como se verifica na nuvem de palavras apresentada na Imagem 1. Essa forma de análise "[...] agrupa as palavras e as organiza graficamente em função da sua frequência" (CAMARGO; JUSTO, 2013, p. 6).

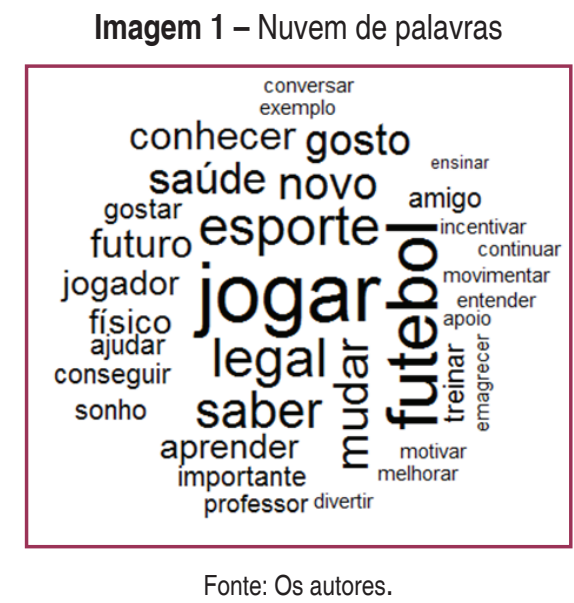

A análise, por meio da nuvem de palavras, demonstra a centralidade e a regularidade do termo mais utilizado pelos sujeitos, denotando que ele se constitui como o núcleo duro, menos flexível, em relação aos outros termos. Em função da sua estabilidade, rigidez e consensualidade presentes nas narrativas dos entrevistados, a palavra "jogar" configura o núcleo central das representações sociais dos entrevistados sobre o projeto. Apoiados em Charlot (2000), compreendemos que todo saber é uma relação com o objeto do saber, ou seja, os sentidos que os adolescentes entrevistados construíram sobre o projeto é proveniente das experiências que estabeleceram com as atividades esportivas por ele ofertadas e que foram mediadas pelo jogar. Para esse autor, "[...] para haver atividade, o sujeito deve mobilizar-se; para que se mobilize, a situação deve apresentar um significado para ele" (CHARLOT, 2000, p. 54).

Entretanto, como o projeto é uma prática social polissêmica, diferentes sentidos se relacionam com as atividades esportivas nele vivenciadas. Dessa maneira, da palavra jogar, que se configura como o núcleo central das representações sociais, derivam variados sentidos (representações periféricas), que demarcam os diferentes usos e apropriações que os praticantes do projeto fazem dele (CERTEAU, 1994). A análise de similitudes ${ }^{8}$, apresentada na Imagem 2, confirma a centralidade da palavra jogar e apresenta outras palavras que estabelecem conexão com ela:

8 Esse procedimento de análise está ancorado na Teoria dos Grafos (elementos combinatórios) e é utilizado por pesquisadores do campo das representações sociais, pois permite identificar as coocorrências entre as palavras, a conexidade que há entre elas, auxiliando na identificação da estrutura da representação (CAMARGO; JUSTO, 2013). 


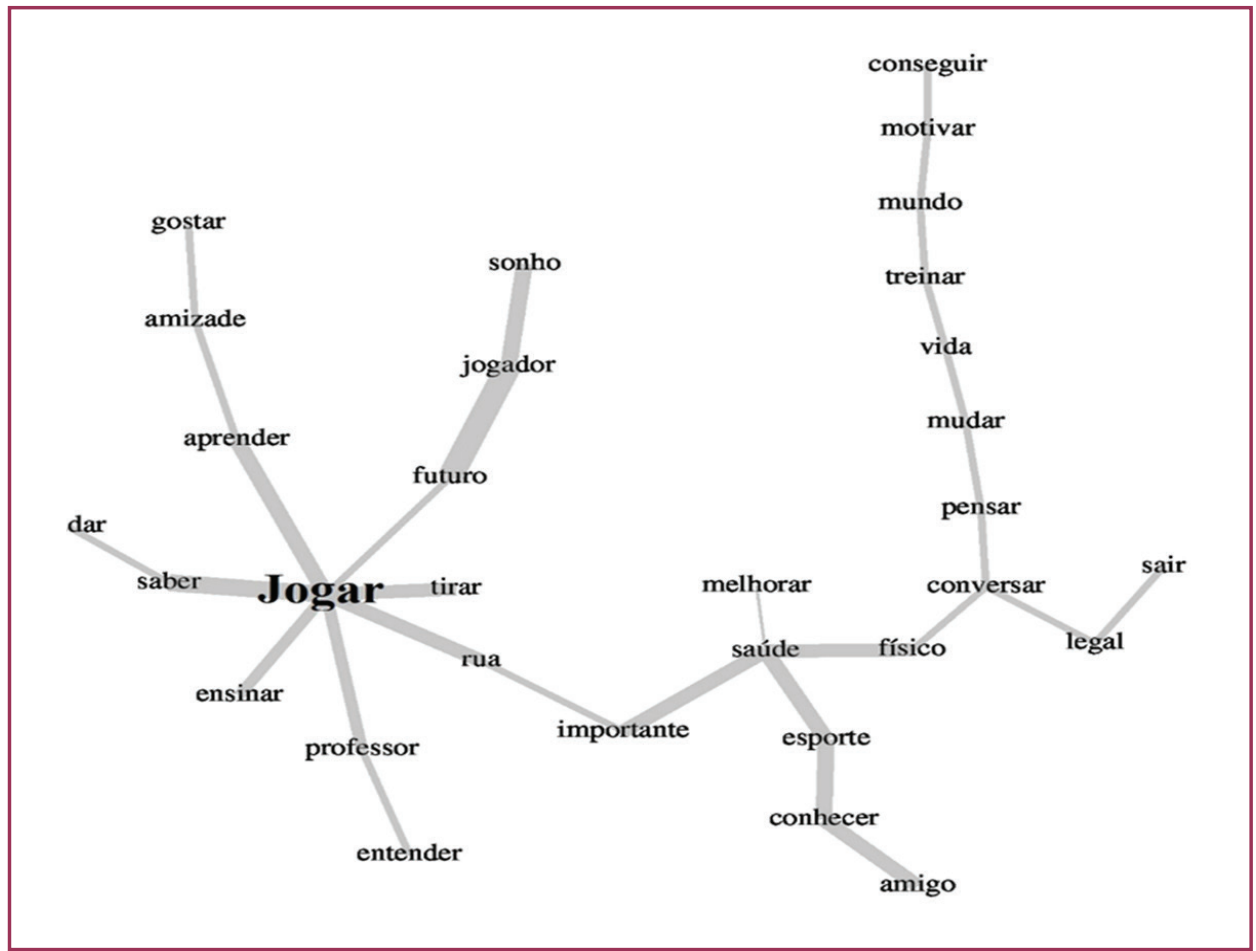

Fonte: Os autores.

A coocorrência de palavras associadas ao jogar denota diferentes sentidos construídos pelos entrevistados nas relações que estabeleceram com as atividades esportivas vivenciadas nas Escolinhas de Esportes. Tal constatação indica que, na relação com os saberes mediados pelo projeto, diferentes figuras do aprender (CHARLOT, 2000) foram valorizadas pelos entrevistados. Percebemos, nesse sentido, um consumo produtivo, nos termos de Certeau (1994), em que os produtos culturais ofertados pelo projeto não foram passivamente assimilados pelos praticantes do cotidiano, pois houve uma dinâmica na recepção, em que eles imprimiram as suas marcas singulares a esses produtos culturais esportivos. Esse consumo dialoga com os interesses e necessidades individuais, disposições culturais, de classe e econômicas que, em grande medida, moldam as representações sociais dos indivíduos. Segundo Charlot (2000), o sentido emerge das relações de apropriação, e os sujeitos valorizam e conferem sentido ao saber quando o colocam em relação com o mundo, consigo mesmos e com os outros.

Apesar de os praticantes do cotidiano produzirem incessantemente diferentes sentidos às atividades físicas e esportivas, historicamente, os projetos sociais têm se pautado em ações externamente orientadas em suas intervenções, pois tendem a considerar os sujeitos das camadas populares como incapazes para pensar e agir sobre si mesmos (MELLO, 2007). Tal tendência tem gerado dificuldade de retenção e altos índices de evasão nesses projetos, decorrentes da divergência entre as intenções dos gestores e as expectativas dos seus usuários. Vianna e Lovisolo (2011, p. 285) afirmam que "[...] a teorização existente sobre as relações do esporte com grupos submetidos a riscos ou marginalizados pela pobreza não parece atentar para o que diz respeito ao entendimento das racionalidades locais". Para Thomassim e Stigger (2013), são as relações sociais de um determinado contexto que dão significados ao esporte e às atividades físicas; portanto, a contextualização e o estabelecimento de acordos com os participantes devem ser uma preocupação dos projetos sociais e de seus gestores. 
Dentre as figuras do aprender valorizadas pelos entrevistados, explicitadas em suas representações sociais, destacam-se: a) a imbricação do eu - em que o saber se instaura no corpo, no domínio de uma atividade; b) a distanciação-regulação - em que os saberes estão demarcados nos dispositivos relacionais, como amizade, solidariedade e respeito; e c) a objetivação-denominação - que diz respeito a um saber objeto, de natureza intelectual. Além dessas figuras do aprender propostas por Charlot (2000), também identificamos representações associadas ao caráter moralista dos projetos sociais, em que predomina a função de afastar crianças e adolescentes de situações de vulnerabilidade social.

Utilizamos a classificação hierárquica descendente para analisar os diferentes sentidos atribuídos ao jogar. Essa forma de análise classifica as palavras em função das relações que estabelecem entre si, agrupando-as em classes de semelhança. Em pesquisas interessadas em estudar o conhecimento do senso comum, tendo em vista o estatuto que elas conferem às manifestações linguísticas, essas classes podem indicar representações sociais (CAMARGO; JUSTO, 2013). Em caráter complementar a esse processo de análise, utilizamos fragmentos das falas dos entrevistados, na intenção de explicitar o conteúdo de suas narrativas.

Na classificação hierárquica descendente, delineada na Imagem 3, é possível perceber os diferentes sentidos que o jogar, núcleo central das representações sociais, assume nas narrativas dos entrevistados:

Imagem 3 - Classificação hierárquica descendente

\begin{tabular}{|c|c|c|c|c|c|}
\hline 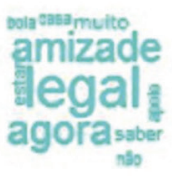 & $\begin{array}{l}\text { gostar yoilei } \\
\text { ensinar } \\
\text { mais } \\
\text { aprender } \\
\text { então monte }\end{array}$ & 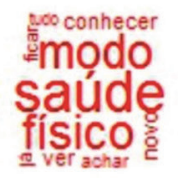 & $\begin{array}{c}\text { estar assim apolo } \\
\text { mundo } \\
\text { gente } \\
\text { menina } \\
\text { bastante forma }\end{array}$ & $\begin{array}{r}\text { significar } \\
\text { dia đ্ } \\
\text { nãovir đ } \\
\text { tirar cá } \\
\text { futebol }\end{array}$ & 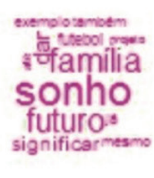 \\
\hline Classe 1 & Classe 2 & Classe 3 & Classe 4 & Classe 5 & Classe 6 \\
\hline$(17,7 \%)$ & $(19 \%)$ & $(15,2 \%)$ & $(15,2 \%)$ & $(20,2 \%)$ & $(12,7 \%)$ \\
\hline
\end{tabular}

Fonte: Os autores.

As classes de palavras 2, 4 e 6, apresentadas na classificação hierárquica descendente, estão associadas à imbricação do eu, figura do aprender centrada no domínio de uma atividade, que se inscreve no corpo. O corpo é um lugar de apropriação do mundo, pois, segundo Charlot (2000), somos sujeitos encarnados dentro de um mundo de situações e significações. Quando somadas, essas classes de palavras representam $46,9 \%$ das representações, entretanto, cada classe apresenta singularidades que denotam diferentes apropriações da figura do aprender em questão.

A classe 2, por exemplo, sinaliza que os entrevistados valorizam o aprendizado da modalidade esportiva que praticam, pois querem jogar cada vez melhor, como evidenciam as seguintes narrativas: "Significa que ele [o projeto] ensina mais para quem não sabe jogar, a gente fica sabendo jogar" (Sujeito 66); "É um aprendizado, para mim, aprender mais sobre o esporte que eu quero" (Sujeito 42); "Quero muito aprender a jogar vôlei, então eu tento bastante me esforçar para aprender (Sujeito 75)"; "O projeto é muito legal, porque me fez gostar de vôlei, que eu nem gostava antes" (Sujeito 72). Para Lovisolo (2001, p. 113), a construção do gosto pelo esporte representa um dos principais motivos para a ação dos indivíduos: 
Se a atividade proposta é um tédio e não cruza com os sonhos, apenas a repressão fará que os sujeitos participem. Se a participação é determinada pela obrigação normativa, podemos obter como resposta a presença ausente, participação muito pequena, com 'p' minúsculo. Estou dizendo então que o esporte lida com 0 estético, com gostos e emoções, do corpo e da performance esportiva, e que não podemos esquecer essa dimensão, talvez hoje a principal.

A classe de palavras 4 denota que aprender a jogar uma modalidade esportiva significa, especialmente para as meninas, possibilidades de mudança e de novas perspectivas de vida, como ilustram as seguintes narrativas: "Significa uma forma de olhar o mundo de outra maneira" (Sujeito 54); "Tudo. Ele muda a gente de uma forma que nem a gente entende" (Sujeito 20); "Significa uma coisa muito legal, que eu consigo ter novos caminhos [...]" (Sujeito 33). Essas representações sociais remetem nossa análise à questão de gênero, aqui compreendida como uma categoria relacional na qual, ao se levar em conta os gêneros, também se consideram as relações de poder, a importância da experiência, da subjetividade e do saber concreto (ARRUDA, 2002).

Embora não possamos afirmar categoricamente, temos indícios de que, no contexto do projeto, aprender a jogar uma modalidade esportiva significa, para as meninas, a possibilidade de romper com relações hierárquicas de poder que as colocam em condições de subalternidade em relação aos meninos. Desnaturalizam-se, com isso, representações que concebem as meninas como geneticamente menos aptas a praticar esportes considerados masculinos, como o futebol e as lutas (DAOLIO, 1997). Aprender a jogar, no cotidiano das Escolinhas de Esportes, propicia o empoderamento das adolescentes, que se sentem mais confiantes e capazes para enfrentar os desafios da vida, como sinalizam as suas falas. Para além das narrativas apresentadas sobre essa classe, esses sentidos puderam ser verificados em conversas estabelecidas pelos pesquisadores com as adolescentes nos festivais promovidos entre as Escolinhas de Esportes de diferentes regionais, onde elas reafirmaram a importância do projeto para as suas vidas. Para Schneider e Bueno (2005, p. 32):

\footnotetext{
É possivel que existam diferentes formas de relação com o saber, o que faz com que as alunas consigam perceber de modo mais positivo o seu aprendizado em relação aos saberes ensinados nas aulas de Educação Física [e nos projetos sociais] [...] talvez seja porque esse espaço se constitua em um dos poucos locais em que tenham maior acesso aos elementos da cultura corporal de movimento como os esportes e jogos [grifo nosso].
}

A classe de palavras 6 associa o jogar, o aprendizado e o desenvolvimento de um determinado esporte com a possibilidade de mobilidade social: "Significa muito, porque meu sonho é ser jogador de futebol e dar um futuro pra minha família" (Sujeito 69); "Significa uma coisa boa pra mim, porque talvez pode ser meu futuro, ser jogador de futebol" (Sujeito 23); "Este projeto significa tudo pra mim, desde pequeno eu sonho em ser jogador de futebol e ter uma vida melhor" (Sujeito 65).

Os discursos que veem o esporte como uma alternativa para a mobilidade social são provenientes, sobretudo, dos sujeitos que participam do projeto nas comunidades mais carentes do município de Vitória. Para Charlot (2000, p. 72), "[...] aprender faz sentido por referência à história do sujeito, às suas expectativas, à sua concepção de vida [...]". O sujeito encontra sentido quando algo que the acontece pode ser posto em relação com outras dimensões de sua vida. Vianna (2007), em sua tese de doutorado, constatou que os adolescentes e 
jovens de comunidades carentes que participam de projetos sociais apostam mais no talento pessoal - seja no esporte, seja na música - para terem um futuro melhor do que no processo de escolarização, pois, com base nos exemplos familiares e de amigos, percebem que 0 investimento nos estudos nem sempre resulta no rompimento com a condição social em que se encontram.

A classe de palavras 1 sinaliza representações sociais relacionadas com a distanciaçãoregulação, figura do aprender que tem como objeto principal as relações interpessoais, expressas, sobretudo, na amizade. As seguintes narrativas evidenciam essa figura do aprender, valorizada no projeto: "O projeto me faz me soltar mais um pouco, fazer mais amizades. Eu não sabia jogar bola e agora estou aprendendo através de um colega meu" (Sujeito 3); "Tem um montão de gente aqui que eu já tinha visto e nunca tinha falado pessoalmente. Eu descobri novas amizades" (Sujeito 33); "Muitas vezes, quando a gente tá, assim, triste, eu venho pro atletismo, aí meu ânimo aumenta, porque tem o pessoal aqui, as meninas me ajudam bastante, elas são muito gente boa" (Sujeito 56). 0 princípio da distanciação-regulação estabelece que quem aprende é o sujeito encarnado, nas interações com os outros, pois são "[...] formas relacionais de saber, como a solidariedade, a amizade e a perseverança que são aprendidas em ato, em situações concretas de experimentação, e não apenas de verbalização" (MELLO; FERREIRA NETO; VOTRE, 2009, p. 79).

Compreendemos que os adolescentes do projeto valorizam aquilo que neles produz efeitos e marcas, pois o saber deixa de ser uma informação desvinculada da sua realidade, tornando-se algo que se passa com eles. Em situações como essas, percebemos que os adolescentes do projeto deram sentido ao que são e ao que lhes acontece, tornando possível a concretização da experiência que, segundo Larrosa Bondía (2002, p. 2), "é o que nos passa, o que nos acontece, o que nos toca", ou seja, o conhecimento é resultado de uma experiência pessoal ligada à atividade que o sujeito realiza. Nessa perspectiva, o aprender, expresso nas narrativas dos adolescentes apresentadas anteriormente, é "afetivo e relacional, definido por sentimentos e emoções em situação e em ato" (CHARLOT, 2000, p. 70).

A classe de palavras 3 relaciona o jogar com um saber de natureza intelectual, o saberobjeto: "aprender pode ser adquirir um saber, no sentido estrito da palavra, isto é, um conteúdo intelectual" (CHARLOT, 2000, p. 59). Nesta figura do aprender, os adolescentes valorizam os conhecimentos que discutem o impacto do jogar sobre a sua saúde, como revelam as seguintes narrativas: "Acho que é um esporte físico, e é bom saber o benefício dele para a minha saúde" (Sujeito 39); "Uma maneira de conhecer sobre as atividades físicas, que são muito importantes para a saúde" (Sujeito 30).

Embora não seja uma abordagem sistematizada e compartilhada em todos os núcleos do projeto, essa figura do aprender é valorizada por alguns adolescentes entrevistados, especialmente aqueles que estão inseridos na Escolinha de Esportes de Jardim da Penha, bairro de classe econômica média alta de Vitória. Enquanto nos bairros de periferia as representações ligadas ao jogar estão mais centradas na ascensão social, no contexto onde a população possui melhor poder aquisitivo, as representações estão associadas à saúde e à estética. Para Spink (1993, p. 90), "[...] é consenso entre os pesquisadores da área que as representações sociais, enquanto produtos sociais, têm de ser sempre referidas às condições de sua produção".

Por fim, a classe de palavras 5 sinaliza que o jogar está articulado com o afastamento dos sujeitos de situações de risco social, como apontam as seguintes narrativas: "Porque tira 
das ruas, tira as pessoas do caminho errado" (Sujeito 9); "Significa uma coisa boa, porque a pessoa não tem nada pra fazer em casa e, se fica lá, no morro, fica se envolvendo com droga, com coisa errada" (Sujeito 14); "[...] uma coisa boa, para incentivar as pessoas a não roubar e não usar drogas" (Sujeito 7). Diferentemente das outras classes de palavras, percebemos que, nas narrativas dos entrevistados, não dá para garantir que as afirmações estão ancoradas nas experiências pessoais, mas em representações sobre projetos sociais, reificadas no imaginário coletivo.

Com base na Análise de Discurso Crítica (ACD) ${ }^{9}$ (FAIRCLOUGH, 2003; RESENDE; RAMALHO, 2006), percebemos, nas narrativas dos adolescentes entrevistados, a presença da unificação, que é uma forma discursiva sustentada pela construção simbólica de unidade. Dentre as estratégias de unificação, destaca-se a padronização, relacionada com a adoção de um referencial padrão partilhado. 0 padrão discursivo partilhado nas narrativas associa-se à representação assistencialista e compensatória dos projetos sociais, cuja função está ligada à proteção de crianças e adolescentes das mazelas sociais advindas das ruas, sobretudo quando esses sujeitos são provenientes das camadas populares. Nesse sentido, o padrão partilhado refere-se à representação de que a rua é perigosa e de que o projeto social é uma forma de proteger crianças e adolescentes desse perigo.

Tendo como referência a modalidade, que indica o grau de comprometimento do indivíduo com aquilo que ele diz, percebemos, nas narrativas apresentadas, um nível elevado de modalidade objetiva. Para Resende e Ramalho (2006, p. 85), nas modalidades objetivas, o sujeito:

[...] não explicita a base subjetiva do seu comprometimento, o efeito disso é a universalização da perspectiva (discurso) defendida, que é tomada tacitamente como verdadeira, uma vez que não há marca dessa perspectiva como sendo uma perspectiva particular.

Percebemos que os educandos utilizam estratégias discursivas que, do ponto de vista moral, são incontestáveis, pois estão cristalizadas pelo senso comum em relação ao objeto da representação: tirar da rua já se consolidou como um ponto pacífico e consensual sobre a função dos projetos sociais, que dificilmente será questionado ou oferecerá resistência. Entretanto, o que prevalece nas narrativas é o discurso indireto, em que a primeira pessoa do singular é substituída pela terceira pessoa (singular/plural), denotando que as representações nem sempre são decorrentes da experiência pessoal, mas, em algumas situações, da construção simbólica de unidade sobre os projetos sociais.

\section{CONSIDERAÇÕES FINAIS}

Analisamos as representações sociais dos participantes do projeto Escolinhas de Esportes de Vitória e compreendemos, assim como Lovisolo (1995), que, sem as experiências do cotidiano e sem as representações dos seus usuários, os projetos podem chegar a avaliações imprecisas e traçar estratégias inadequadas de intervenção. As representações sociais identificadas neste estudo apresentam, como núcleo central, o termo "jogar". Os sentidos vinculados ao jogar estão relacionados com a amizade, 0 aprender as modalidades esportivas, a estética/saúde, a ascensão social e novas perspectivas de vida, no caso das adolescentes. Esses sentidos foram construídos por meio das experiências que os adolescentes 
estabeleceram com as atividades esportivas mediadas pelo projeto e que se materializaram em diferentes figuras do aprender.

Entretanto, o sentido associado à função moralista dos projetos sociais, de tirar os adolescentes da rua, não está vinculado às experiências pessoais. Com base na Análise Crítica do Discurso, verificamos que as narrativas foram construídas na terceira pessoa (singular e plural), explicitando uma modalidade objetiva, em que os sujeitos não expõem a base subjetiva do seu comprometimento com aquilo que dizem.

As constatações desta pesquisa apontam para uma versão não categórica do papel da iniciação esportiva em relação a comportamentos, atitudes e saberes dos iniciantes, levando em consideração a apropriação imprimida pelos participantes às atividades ofertadas pelo projeto. Por outro lado, a análise das narrativas, ilustradas pelos excertos que incluímos no texto, sugere que o peso das representações sociais, geradas no diálogo, diminui o tom de certeza dos sujeitos em relação aos tópicos discutidos e pode favorecer acordos de falas.

A análise desenvolvida neste estudo conseguiu identificar núcleos discursivos relativamente consensuais, mas isso não garante que as frases analisadas sintetizem outros saberes, além dos saberes discursivos. Portanto, novas abordagens do fenômeno aqui analisado podem ganhar com o confronto de saberes manifestos na enunciação com comportamentos e atitudes flagrados em situação real de jogo.

\section{REFERÊNCIAS}

ABRIC, Jean-Claude. A abordagem estrutural das representações sociais. In: MOREIRA, Antonia Silva Parede; OLIVEIRA, Denize Cristina de (Org.). Estudos interdisciplinares de representação social. Goiânia: AB, 2000. p. 27-38.

ABRIC, Jean-Claude. Abordagem estrutural das representações sociais: desenvolvimentos recentes. In: CAMPOS, Pedro Humberto Faria; LOUREIRO, Marcos Correia da Silva (Org.). Representações sociais e práticas educativas. Goiânia: Ed. UCG, 2003. p. 37-57.

ARRUDA, Angela. Teoria das representações sociais e teorias de gênero. Cadernos de Pesquisa, n. 117, p. 127-147, nov. 2002.

BELO HORIZONTE. Prefeitura Municipal. Secretaria Municipal Adjunta de Assistência Social. Dicionário de termos técnicos da assistência social. Belo Horizonte: Ascom, 2007.

BURAK, Solum Donas. Adolescência e juventude na América Latina. In: BURAK, Solum Donas. Adolescência e juventude na América Latina. Catargo: Livro Universitário Regional, 2001. p. $118-130$

CAMARGO, Brigido Vizeu; JUSTO, Ana Maria. Tutorial para uso do software de análise textual Iramuteq. Florianópolis: Universidade Federal de Santa Catarina, 2013.

CARNEIRO, Carla Bronzo; VEIGA, Laura. 0 conceito de inclusão, dimensões e indicadores. Belo Horizonte: Secretaria Municipal de Coordenação da Política Social, 2004. (Pensar BH/Política Social, 2). 
CASTRO, Suélen Barbosa; SOUZA, Doralice Lange. Significados de um projeto social esportivo: um estudo a partir das perspectivas de profissionais, pais, crianças e adolescentes. Movimento, v. 17, n. 4, p. 145-163, out./dez. 2011.

CERTEAU, Michel. A invenção do cotidiano: artes de fazer. 8 ed. Petrópolis: Vozes, 1994.

CHARLOT, Bernard. Da relação com o saber: elementos para uma teoria. Porto Alegre: Artes Médicas, 2000.

CHARLOT, Bernard. A noção de relação com o saber: bases de apoio teórico e fundamentos antropológicos. In: CHARLOT, Bernard. (Org.). Os jovens e o saber: perspectivas mundiais. Porto Alegre: Artmed, 2001. p. 15-31.

DAOLIO, Jocimar. Cultura, educação física e futebol. Campinas: Editora da Unicamp, 1997.

DEMO, Pedro. Cidadania tutelada e cidadania assistida. Campinas: Autores Associados, 1995.

FAIRCLOUGH, Norman. Analysing discourse: textual analysis for social research. London/ New York: Routledg, 2003.

FREITAS, Maria Virginia de; PAPA, Fernanda de Carvalho. Políticas públicas: juventude em pauta. São Paulo: Cortez, 2000.

GONÇALVES, Maria Alice Rezende. A Vila Olímpica da Verde-e-Rosa. Rio de Janeiro: Editora FGV, 2003.

GUEDES, Simoni Lahud et al. Projetos sociais esportivos: notas de pesquisa. In: ENCONTRO REGIONAL DE HISTÓRIA, 12., 2006, Niterói. Anais... Rio de Janeiro: ANPUH, 2006. p. 1-10.

LARROSA BONDÍA, Jorge. Notas sobre a experiência e o saber de experiência. Revista Brasileira de Educação, n. 19, p. 20-28, jan./abr. 2002.

LOVISOLO, Hugo Rodolfo. Mediação: esporte rendimento e esporte na escola. Movimento, v. 7, n. 15, p. 107-116, 2001.

LOVISOLO, Hugo Rodolfo. Normas, utilidades e gosto na aprendizagem. In: VOTRE, Sebastião Josué; COSTA, Vera Lucia de Menezes (Org.). Cultura, atividade corporal e esporte. Rio de Janeiro: Editora Gama Filho, 1995. p. 213-232.

MELLO, André da Silva. Projeto Esporte Cidadão: avaliação e reorientação. 2007. 164 f. Tese (Doutorado em Educação Física) - Universidade Gama Filho, Rio de Janeiro, 2007.

MELLO, André da Silva.; FERREIRA NETO, Amarílio; VOTRE, Sebastião Josué. Intervenção da educação física em projetos sociais: uma experiência de cidadania e esportes em Vila Velha (ES). Revista Brasileira de Ciências do Esporte, v. 31, p. 75-91, set. 2009.

MELO, Marcelo Paula de. Lazer, esporte e cidadania: debatendo a nova moda do momento. Movimento, v. 10, n. 2, p. 105-122, maio/ago. 2004.

MELO, Marcelo Paula de. Políticas sociais de esporte e lazer, sociedade civil e teoria de estado: a defesa da radicalidade gramsciana. Motrivivência, v. 24, n. 38, p. 59-74, jun. 2012.

MOSCOVICl, Serge. Representações sociais: investigações em psicologia social. Petrópolis: Vozes, 2003. 
RESENDE, Viviane de Melo; RAMALHO, Viviane. Análise de discurso crítica. São Paulo: Contexto, 2006.

SÁ, Celso Pereira de. 0 núcleo central das representações sociais. 2. ed. Petrópolis/RJ: Vozes, 2002.

SCHNEIDER, Omar; BUENO, José Geraldo Silveira. A relação dos alunos com os saberes compartilhados nas aulas de educação física. Movimento, v.11, n. 1, p. 23- 46, 2005.

SILVEIRA, Juliano. Considerações sobre o esporte e o lazer: entre direitos sociais e projetos sociais. Licere, v. 16, n. 1, p. 1-22, mar. 2013.

SPINK, Mary Jane. O estudo empírico das representações sociais. In: SPINK, Mary Jane (Org.). 0 conhecimento no cotidiano: as representações sociais na perspectiva da psicologia social. São Paulo: Brasiliense, 1993. p. 85-108.

THOMASSIM, Luis Eduardo Cunha. Os sentidos da exclusão social na bibliografia da educação física brasileira. Movimento, v. 13, n. 1, p. 151-178, 2007.

THOMASSIM, Luis Eduardo Cunha. Uma alternativa metodológica para a análise dos projetos sociais esportivos. 2006. In: ENCONTRO NACIONAL DE RECREAÇÃO E LAZER, 18, 2006, Curitiba. Anais... Curitiba: PUCPR, 2006. CD ROM.

THOMASSIM, Luis Eduardo Cunha; STIGGER, Marcos Paulo. Entre o "serve" e o "significa": uma análise sobre expectativas atribuídas ao esporte em projetos sociais. Licere, v. 16, n. 2, p. 1-33, jun. 2013.

VIANNA, José Antonio. Esporte e camadas populares: inclusão e profissionalização. 2007. 238 f. Tese (Doutorado em Educação Física) - Universidade Gama Filho, Rio de Janeiro, 2007.

VIANNA, José Antonio; LOVISOLO, Hugo Rodolfo. A inclusão social através do esporte: a percepção dos educadores. Revista Brasileira de Educação Física e Esporte, v. 25, n. 2, p. 285-296, abr./jun. 2011.

VIANNA, Jose Antonio; LOVISOLO, Hugo Rodolfo. Projetos de inclusão social através do esporte: notas sobre avaliação. Movimento, v. 15, n. 3, p. 145- 162, jul./set. 2009.

VILAÇA, Murilo Mariano; GAWRYSZEWSKI, Bruno; PALMA, Alexandre. Crítica à panaceia pedagógico-desportiva. Educação e Filosofia, v. 28, n. 55, p. 169-198, jan./jun. 2014.

ZALUAR, Alba. Cidadãos não vão ao paraíso. São Paulo: Ed. Escuta, 1994. 
Apoio: 